\title{
The Metabolism of Triglycerides by Spores of Penicillium roqueforti
}

\author{
By R. C. LAWRENCE* \\ The National Institute for Research in Dairying, Shinfield, Reading
}

(Accepted for publication 9 August 1966)

\begin{abstract}
SUMMARY
The ability of suspensions of washed spores of Penicillium roqueforti to oxidize triglycerides was markedly stimulated by L-proline, L-alanine and L-serine, although all the sources of nitrogen tested were effective over extended periods to different degrees. The rate of oxidation was further increased by the addition of certain sugars, although these were without effect in the absence of a nitrogen source. The same compounds that stimulated methylketone formation from triglycerides also promoted the rapid germination of spores, suggesting that common reactions were involved. The maximum yield of methylketone obtained was $25 \%$ from trioctanoin and trihexanoin at $\mathrm{pH} 6.0$, with lower yields from tridecanoin, tributyrin and trilaurin. The addition of sodium azide, and to a lesser extent of 2,4-dinitrophenol and certain organophosphorus compounds, inhibited the oxidation of triglycerides. The possible role of fungal esterases in spore germination is discussed.
\end{abstract}

\section{INTRODUCTION}

Growing cultures of Penicillium glaucum have been shown to oxidize up to $15 \%$ of synthetic triglycerides containing $\mathrm{C}_{4}$ to $\mathrm{C}_{12}$ fatty acids to the corresponding methylketones with one less carbon atom (Acklin, 1929; Thaler \& Eisenlohr, 1941). The first step in the oxidation is presumably the hydrolysis of the triglyceride, since the formation of extracellular esterases is well documented (e.g. Morris \& Jezeski, 1953; Alford, Pierce \& Suggs, 1964). It is not clear however from these investigations whether the initial hydrolysis of the triglyceride and the subsequent metabolism of the liberated fatty acid is the result of spore activity or of mycelial activity. Gehrig \& Knight $(1958,1963)$ considered that spores of Penicillium roqueforti are able to oxidize fatty acids but that the capacity to form methylketones disappears rapidly and progressively as the spores germinate. On the other hand Lawrence (1965a) found that the slow rate of formation of heptan-2-one from octanoic acid by washed spore suspensions of $P$. roquefort $i$ was markedly increased by the addition of the same specific amino acids and sugars that have been shown to stimulate fungal germination.

The germination of sporangiospores of Rhizopus arrhizus (Weber \& Ogawa, 1965), R. stolonifer (Weber, 1962) and the conidia of Aspergillus niger (Yanagita, 1957; Miller, 1962) is strongly stimulated by L-proline and less effectively by some other amino acids. For $A$. niger alanine is also stimulatory, but for $R$. arrhizus proline can be replaced by ornithine, arginine or asparagine only when phosphate is also present. Cochrane, Cochrane, Simon \& Spaeth (1963) showed that, in addition to glucose

* Permanent address: The Dairy Research Institute (N.Z.), Palmerston North, New Zealand. 
and a nitrogen source, the macrospores of Fusarium solani required a factor present in yeast extract which could be partially replaced by several amino acids but not by carbohydrates.

Germination has also been associated with the decrease in fungal spore lipid which occurs during incubation (Farkas \& Ledingham, 1959; Cochrane, Cochrane, Collins \& Serafin, 1963; Jack, 1964). Lipids are a prominent constituent of several species of fungi (Allen, 1965) and the activation or synthesis of an esterolytic system and its subsequent attack upon the lipid of the spore coat may be related to the swelling and increase in permeability of fungal spores which precedes germination (Yanagita, 1957; Ekundayo \& Carlisle, 1964).

The present paper describes the effect of amino acids and sugars upon the ability of suspensions of washed spores of Penicillium roqueforti to metabolize triglycerides containing short-chain fatty acids. The possibility of a relationship between the hydrolytic activity of the spores and their subsequent germination was also investigated.

\section{METHODS}

General. Penicillium roqueforti ATcc 6989 (American Type Culture Collection, Washington, D.C.) used in previous work on the oxidation of fatty acids (Lawrence, $1965 a$, 1966), was grown on slopes of Czapek-Dox agar or malt agar (Oxoid) at $22^{\circ}$. After incubation for 7-10 days the spores were gently dislodged with an inoculation needle and quickly washed in sterile water by centrifugation. The washed spores were resuspended in water or phosphate buffer to give an extinction of 0.6 at $650 \mathrm{~m} \mu$ which corresponded to about $5 \times 10^{8}$ spores $/ \mathrm{ml}$. as determined from a calibration curve of haemocytometer counts of spores against extinction.

Samples of these spore suspensions $\left(10 \mathrm{ml}\right.$.) were incubated at $30^{\circ}$, the optimal temperature for oxidation, with equimolecular amounts of triglycerides (normally $30 \mu$ moles) which were dispersed by shaking in stoppered bottles $(100 \mathrm{ml}$.). Streptomycin $(0.25 \mathrm{mg} . / \mathrm{ml}$.) was added to prevent bacterial growth. Germination (appearance of the germ tube) was determined by microscopic observation of samples of the spores stained with dilute carbol fuchsin.

Cell-free extracts of spores. Sufficient $0.05 \mathrm{M}$-phosphate $+0.05 \mathrm{M}$-sucrose buffer $(\mathrm{pH} 7 \cdot 0)$ was added at $4^{\circ}$ to spores $(1 \mathrm{~g}$. wet wt) and acid-washed sand $(2 \mathrm{~g}$.$) in$ a pre-cooled mortar to form a thick paste. This was ground for $5 \mathrm{~min}$., more buffer added to a final volume of $5 \mathrm{ml}$. and the suspension centrifuged at $1200 \mathrm{~g}$ for $10 \mathrm{~min}$., the supernatant fluid being used.

Measurement of oxygen uptake. Manometric measurements of respiration were made by the direct Warburg method at $30^{\circ}$. The total volume in each Warburg flask was usually $3.0 \mathrm{ml}$. spore suspension + substrate, with $0.2 \mathrm{ml} .20 \%$ (w/v) KOH in the centre well.

Estimation of methylketones. Methylketone concentrations were determined at intervals during the experiments by adding $1 \mathrm{ml}$. of the contents of a $100-\mathrm{ml}$. stoppered bottle containing spore suspension and substrate into $2 \mathrm{ml}$. 2,4-dinitrophenyl hydrazine solution $(2 \mathrm{~g} . / 1.2 \mathrm{~N}-\mathrm{HCl})$ in a stoppered test-tube. After $30 \mathrm{~min}$. the 2,4-dinitrophenyl hydrazone was extracted and the methylketone subsequently estimated by the method previously described (Lawrence, 1965 b).

Estimation of esterase. Esterase activity was determined by a quantitative thin-layer 
agar diffusion method at $30^{\circ}$ (Lawrence, Fryer \& Reiter, 1966) by measuring the zones of clearing (recorded in $\mathrm{mm}$.) of a $0.1 \%$ emulsion of tributyrin in agar buffered with $0.05 \mathrm{M}$ phosphate ( $\mathrm{pH} 8)$.

Hydrolysis of $o$-nitrophenylbutyrate was measured by the spectrophotometric estimation of the liberated $o$-nitrophenol at $410 \mathrm{~m} \mu$ with $1 \mathrm{~cm}$. cuvettes and total volumes of $3.2 \mathrm{ml}$. Assay mixtures contained $100 \mu$ moles tris $+\mathrm{HCl}$ buffer and $7.5 \mu$ moles $o$-nitrophenyl butyrate (added as a solution in $0.2 \mathrm{ml}$. methanol). In preliminary experiments $p$-nitrophenyl acetate was also used, but the very low esterase activities of the cultures with this substrate were of the same order as the rate of spontaneous hydrolysis of the substrate at $\mathrm{pH} 7$. The more stable $o$-nitrophenylbutyrate did not spontaneously hydrolyze although non-enzymic hydrolysis in presence of certain nitrogen compounds, e.g. proline and ammonium sulphate, had to be taken into account. When the rates of hydrolysis (change in extinction/min.) were appropriately corrected for spontaneous hydrolysis and non-enzymic hydrolysis, the esterase from Penicillium roquefort $i$ appeared to be equally active against $o$-nitrophenylbutyrate and $p$-nitrophenylacetate. In the present work it appeared that only one enzyme was involved in the hydrolysis of the emulsified tributyrin and of the soluble $o$-nitrophenylbutyrate; the general term esterase has therefore been used to cover both types of activity.

Chemicals. Chromatographically pure glycerides were obtained from Sigma Chemical Co. (St Louis, Mo., U.S.A.), Tween 20 (polyoxyethylene sorbitan monolaurate) from Honeywill-Atlas Ltd. (Carshalton, Surrey), $p$-nitrophenyl acetate and $o$-nitrophenyl butyrate from British Drug Houses Ltd. Bactopeptone, Casamino acids (Difco), amino acids and sugars (British Drug Houses Ltd.) were either autoclaved or Seitz-filtered (Ford's Sterimats, A. Gallenkamp and Co. Ltd.). Chloramphenicol was obtained from Parke, Davis and Co. (Detroit, Mich.). Di-isopropylfluorophosphate (DFP) and diethyl $p$-nitrophenylphosphate (E 600) were gifts from Dr G. C. Cheeseman and Dr P. Andrews (N.I.R.D.), respectively.

\section{RESULTS}

\section{Effect of shaking spore suspensions}

Although shaking the spore suspensions increased the oxygen uptake and methylketone formation, the spores tended to clump together and replicate experiments showed considerable variation. Reproducible results were obtained by using 100-ml. medical flat bottles, sloped to give the maximum surface area of solution.

\section{Activation of spores}

Spores from 5-day cultures were harvested, washed and suspended in phosphate buffer ( $\mathrm{pH}$ 6.5). These spores oxidized trioctanoin extremely slowly, whereas equivalent amounts of octanoic acid were readily oxidized, indicating that the hydrolytic activity of the spores for triglycerides was extremely low. The addition of Casamino acids or specific amino acids to the spore suspensions markedly increased both oxygen uptake (Fig. 1) and methylketone formation (Fig. 2) after an initial lag of at least $5 \mathrm{hr}$. This lag was shorter in the presence of Casamino acids than with any single amino acid, but L-proline stimulated methylketone formation to a greater extent over a period of $24 \mathrm{hr}$. Even small amounts of L-proline $(1 \mu \mathrm{mole} / 10 \mathrm{ml}$.) were effective; 
about $100 \mu$ moles $/ 10 \mathrm{ml}$. were optimal. Whereas the lag before oxidation of fatty acids occurred was less than $2 \mathrm{hr}$, no mixture of stimulatory compounds was able to decrease the lag period with triglycerides below $5 \mathrm{hr}$, presumably because the additional step of esterase formation or activation was involved. L-alanine was nearly as effective as Casamino acids followed by L-serine, L-arginine, L-glycine, L-leucine, L-glutamic acid, L-asparagine, L-glutamine, L-aspartic acid, L-ornithine, in decreasing order of effectiveness. Although other sources of nitrogen tested did not stimulate the oxidation

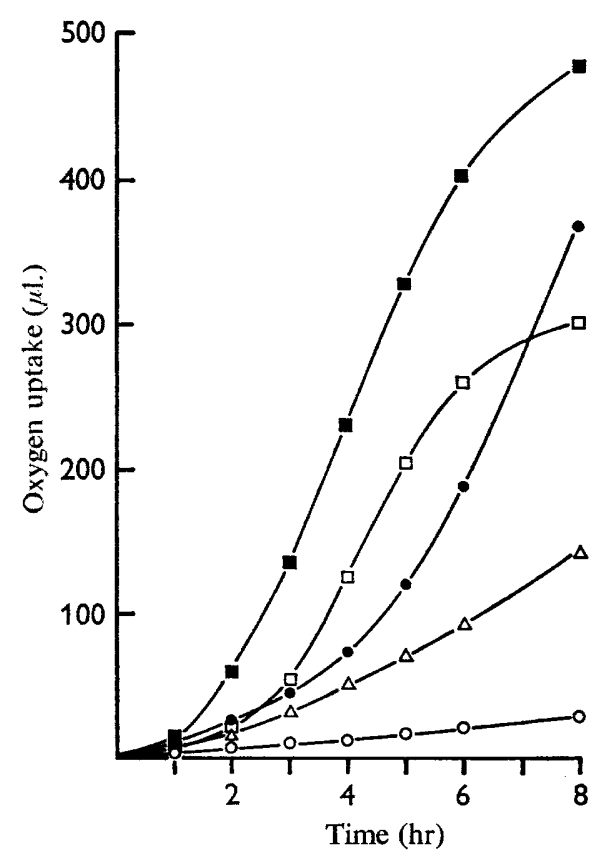

Fig. 1

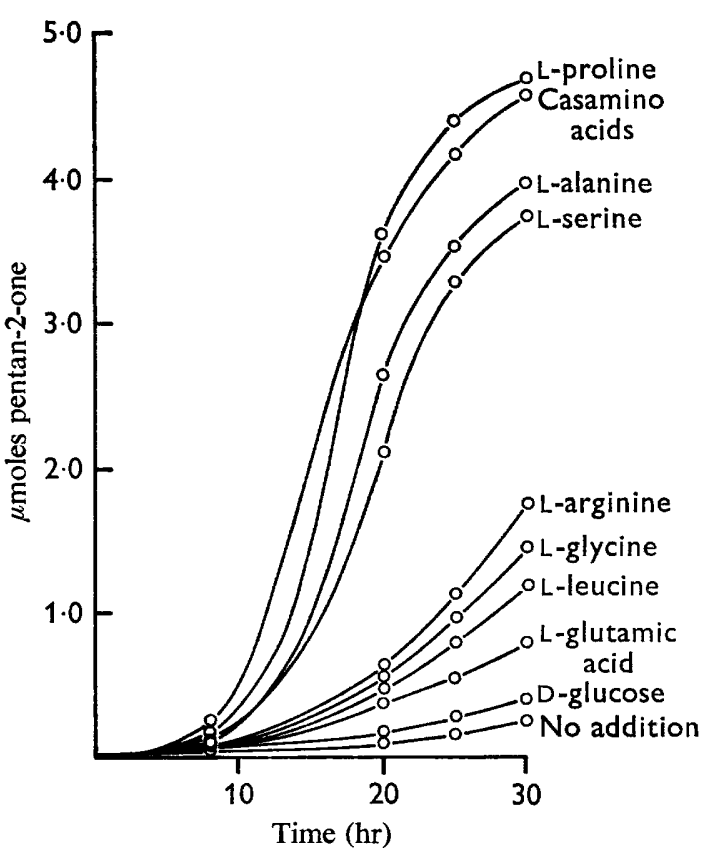

Fig. 2

Fig. 1. The oxidation of octanoic acid ( $9 \mu$ moles) and trioctanoin ( $3 \mu$ moles) by washed 6-day spores $\left(1.5 \times 10^{9}\right)$ of Penicillium roqueforti at $\mathrm{pH} 6.0(100 \mu \mathrm{moles}$ phosphate buffer). Each flask contained either octanoic acid $(\square-\square)$, octanoic acid $+0.05 \mathrm{~g}$ casamino acids

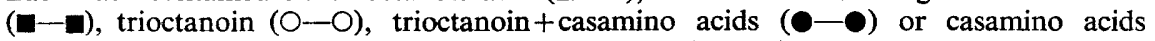
only $(\triangle-\triangle)$. Total volume $3 \mathrm{ml}$. Endogenous respiration deducted.

Fig. 2. The effect of amino acids ( $200 \mu$ moles) on the formation of pentan-2-one from trihexanoin $\left(30 \mu\right.$ moles) by washed 7 -day spores $\left(3 \times 10^{9}\right)$ of Penicillium roqueforti at $\mathrm{pH} 6.0$ ( $200 \mu$ moles phosphate buffer). Total volume $10 \mathrm{ml}$.

of triglycerides in the first $24 \mathrm{hr}$ of incubation, oxidation was markedly increased after $48 \mathrm{hr}$, to various extents, by L-valine, ammonium sulphate, potassium nitrate, L-hydroxyproline, L-phenylalanine, L-lysine, L-threonine, L-methionine, L-histidine, in that order. After $72 \mathrm{hr}$ the yield of pentan-2-one from trihexanoin in the presence of potassium nitrate was significantly greater than with L-proline (Fig. 3).

In the absence of a source of nitrogen, none of the sugars added to the spore suspensions was stimulatory in the first $24 \mathrm{hr}$. In the presence of a nitrogen source, however, some sugars were remarkably effective even when the nitrogen compound was not stimulatory by itself. Thus D-galactose, D-glucose or D-xylose in the presence of potassium nitrate markedly activated the oxidation of trihexanoin to pentan-2-one; 
sucrose and maltose were less effective; D-ribose and lactose were virtually without effect (Fig. 4).

The time of harvesting the spores had no significant effect upon the rate of oxidation of triglycerides, in marked contrast to the oxidation of fatty acids (Lawrence, 1966). The hydrolytic step appeared to be a function of spore germination and might therefore be expected to be independent of the age of the spore. However, although a source of nitrogen was essential for formation of mycelium, spores in the absence of stimulatory compounds oxidized triglycerides very slowly to methylketone (up to $5 \%$ after 6 days) without any obvious morphological change.

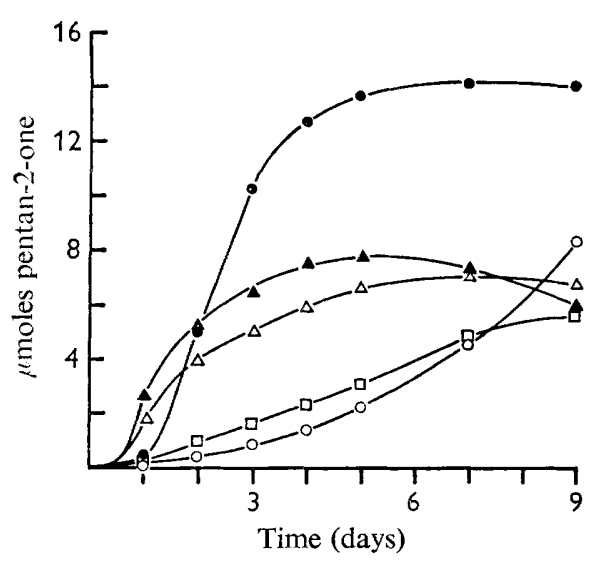

Fig. 3

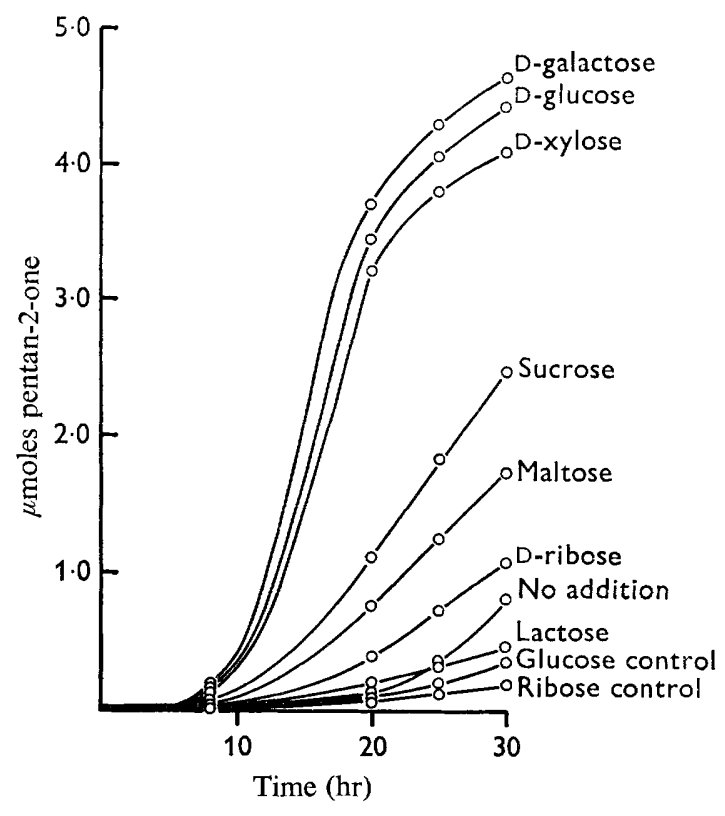

Fig. 4

Fig. 3. The formation of pentan-2-one from trihexanoin ( $30 \mu$ moles) over extended periods by washed 7 -day spores $\left(3 \times 10^{9}\right)$ of Penicillium roqueforti at $\mathrm{pH} 6.0(200 \mu$ moles phosphate buffer) in the presence of $100 \mu$ moles glucose $(\square-\square)$, alanine $(\triangle-\Delta)$, proline $(\boldsymbol{\Delta}-\mathbf{\Delta})$, $\mathrm{KNO}_{3}(-)$, and in the absence of stimulating compounds $(\mathrm{O}-\mathrm{O})$. Total volume $10 \mathrm{ml}$.

Fig. 4. The effect of sugars on the formation of pentan-2-one from trihexanoin by spores of Penicillium roqueforti in the presence of $\mathrm{KNO}_{3}$. Each flask contained $3 \times 10^{9}$ spores, $200 \mu$ moles phosphate buffer (pH 6.0), $200 \mu$ moles of each sugar, $100 \mu$ moles $\mathrm{KNO}_{3}$. Total volume $10 \mathrm{ml}$. Control flasks containing glucose or ribose, respectively, but not $\mathrm{KNO}_{3}$, are also shown.

\section{Effect of Seitz filtration on amino acid solutions}

Solutions of amino acids which had been Seitz-filtered were considerably more active than were autoclaved solutions in stimulating the oxidation of triglycerides by spores (Fig. 5). Distilled water that had been Seitz-filtered was also stimulatory after an extended lag period but only in the presence of a nitrogen source. This confirmed the results of earlier work that Seitz-filtered solutions may contain a factor which is stimulatory to the germination of fungal spores (Farkas \& Ledingham, 1959; Lawrence, 1966) and which may be identical with a partially characterized factor extracted from 
cotton which permits the rapid germination of rust uredospores (Atkinson \& Allen, 1966). Since, however, the effect of Seitz-filtered solutions on the oxidation of triglycerides varied, autoclaved solutions were used in the experiments reported in this paper even although the rate of oxidation was considerably lower.

\section{Esterase activity}

The extremely low esterase activity found in the spore suspensions was unexpected since Penicillium roqueforti was strongly esterolytic when grown on standard tributyrin agar or butterfat + Victoria Blue agar. However, this difference in activity as between solid and liquid media has also been observed with bacterial lipases (O'Leary \& Weld, 1964). Fodor \& Chari (1949) found that lipolytic activity of $P$. roqueforti in liquid cultures was very weak even under optimal conditions.

Table 1. Penicillium roqueforti: the effect of stimulatory compounds on the esterase activity of spores, formation of heptan-2-one from trioctanoin and growth of mycelium

Each flask contained $3 \times 10^{\circ}$ spores, $30 \mu$ moles trioctanoin, $200 \mu$ moles phosphate buffer (pH 6.0), $200 \mu$ moles amino acid or $0.1 \mathrm{~g}$. Casamino acid, $200 \mu$ moles glucose, distilled water to $10 \mathrm{ml}$.: time of incubation $20 \mathrm{hr}$. Esterase activity for substrate $o$-nitrophenylbutyrate (o-NPB) is expressed as rate of change of extinction/min. $X$ is the diameter of the zone of clearing of tributyrin emulsion $(0 \cdot 1 \%)$ minus the diameter of the well.

\begin{tabular}{|c|c|c|c|c|}
\hline \multirow[b]{2}{*}{ Addition } & \multicolumn{2}{|c|}{ Esterase activity } & \multirow[b]{2}{*}{$\begin{array}{l}\text { Heptan-2-one } \\
\text { ( } \mu \text { moles })\end{array}$} & \multirow[b]{2}{*}{ Mycelium* } \\
\hline & $o$-NPB & $\begin{array}{c}\text { Tributyrin } \\
\left(X^{2}\right)\end{array}$ & & \\
\hline - & 0.01 & 0.8 & $0 \cdot 14$ & - \\
\hline Glucose & 0.01 & 0.9 & 0.15 & - \\
\hline Alanine & 0.04 & $1 \cdot 2$ & 0.37 & + \\
\hline Alanine + glucose & 0.07 & $2 \cdot 6$ & 0.79 & + \\
\hline Ammonium sulphate & 0.02 & 0.8 & 0.21 & - \\
\hline Ammonium sulphate + glucose & 0.02 & $0 \cdot 8$ & 0.40 & - \\
\hline Casamino acid & $0 \cdot 10$ & $2 \cdot 9$ & 0.90 & + \\
\hline Casamino acid + glucose & $0 \cdot 10$ & $2 \cdot 6$ & $1 \cdot 32$ & + \\
\hline
\end{tabular}

Suspensions of Penicillium roqueforti spores in water, phosphate buffer or solutions of sugars did not germinate. Such suspensions were only weakly active against tributyrin and $o$-nitrophenylbutyrate but nevertheless oxidized triglycerides very slowly during a longer period of incubation. The addition of stimulatory compounds such as Casamino acids and L-alanine resulted in a slight increase in the esterase activity of the suspension, although methylketone formation from triglycerides (Table 1) and the rapid germination (i.e. within $24 \mathrm{hr}$ ) of the spores was greatly stimulated. No increase in esterase activity was detected until after a lag of at least $6 \mathrm{hr}$; the activity reached a maximum after about $24 \mathrm{hr}$. Attempts to increase esterase production by germinating the spores in complex media such as Bactopeptone and yeast extract were unsuccessful. The addition of butterfat or tributyrin to growing cultures of Penicillium roqueforti did not enhance esterase production, in contrast to earlier reports (Goodman, 1950; Imamura \& Kataoka, 1963) that fungal lipases are adaptive enzymes. 


\section{Effect of phosphate}

Although suspensions of spores harvested from growth on malt agar did not require added phosphate for the initiation of oxidation of triglycerides in the first $24 \mathrm{hr}$, the rate of oxidation by spores harvested from Czapek-Dox agar was markedly stimulated by small amounts of phosphate $(0 \cdot 1 \mu \mathrm{mole} / \mathrm{ml}$.) and was further increased by higher concentrations (Fig. 6). After $48 \mathrm{hr}$, however, considerable amounts of methylketone were formed in the absence of phosphate and after 6 days a maximum of $18 \%$ of the trihexanoin had been oxidized to penta-2-one. At no stage was the yield of methylketone as great as with added phosphate.

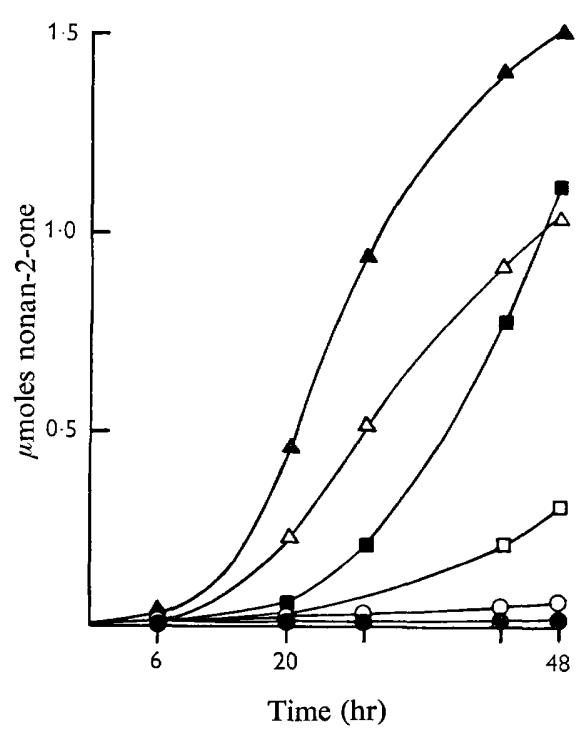

Fig. 5

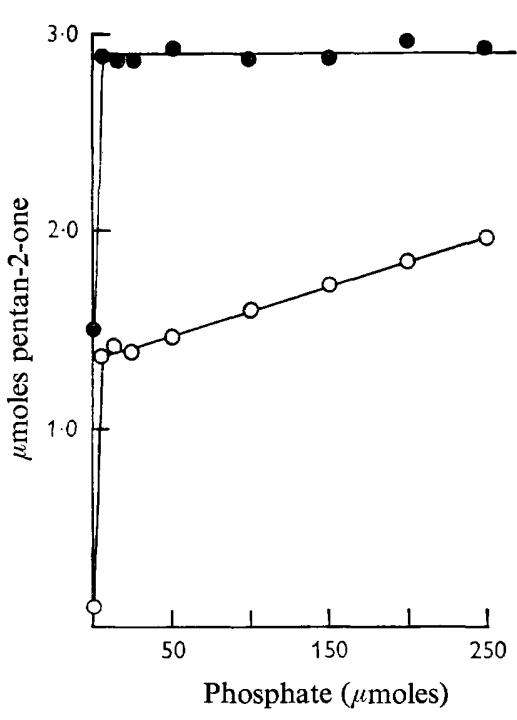

Fig. 6

Fig. 5. The effect of Seitz-filtered solutions on the formation of nonan-2-one from tridecanoin by spores of Penicillium roqueforti in the presence of proline. Each flask contained $6 \mathrm{ml}$. spore suspension $\left(3 \times 10^{9}\right.$ spores), $30 \mu$ moles tridecanoin, $2 \mathrm{ml}$. phosphate buffer (pH 6.0;200 $\mu$ moles), $1 \mathrm{ml}$. autoclaved proline solution $(200 \mu$ moles) and $1 \mathrm{ml}$. autoclaved water $(\square-\square)$ or Seitz-filtered water $(\square--)$; glucose $(200 \mu$ moles $)$ solution $(\triangle-\Delta)$ or Seitz-filtered glucose solution $(\boldsymbol{\Delta}-\mathbf{\Delta})$. Control flasks containing Seitz-filtered water $(\mathrm{O}-\mathrm{O})$ and Seitz-filtered glucose solution (-) but not proline are also shown.

Fig. 6. Effect of phosphate concentration on the formation of pentan-2-one from trihexanoin $\left(30 \mu\right.$ moles) by washed 7 -day spores $\left(3 \times 10^{9}\right)$ after growth on Czapek-Dox agar slopes, at pH $6.0(50 \mu$ moles maleateb uffer $)$ in the presence of Casamino acids $(0.1 \mathrm{~g}$.$) .$ Total volume $10 \mathrm{ml}$. Times of incubation $24 \mathrm{hr}(\mathrm{O}-\mathrm{O})$ and $48 \mathrm{hr}(\mathrm{O}-\mathrm{O})$.

There was a slight but significantly greater difference in the esterase activity of spores harvested after growth on malt agar than of those from Czapek-Dox agar. The two media contain different sugars which may have affected the relative amounts of available phosphate in the spores and their esterolytic behaviour. Grover (1964) found that the characteristics of spores of Aspergillus flavus, including their requirements for germination, were apparently greatly influenced by the cultural conditions during spore formation. 


\section{Effect of $\mathrm{pH}$ value}

The rate at which methylketones were formed from triglycerides by spores activated by $0 \cdot 1 \%$ Casamino acids increased rapidly below $\mathrm{pH} 7 \cdot 0$. Trihexanoin and trioctanoin were most readily oxidized at $\mathrm{pH} 6.0$ (Fig. 7), approximately $25 \%$ of each triglyceride being oxidized to the corresponding methylketone after 6-10 days. Lower yields of methylketone were obtained from tributyrin $(8 \%$ at $\mathrm{pH} 5 \cdot 5)$, tridecanoin $(14 \%$ at pH 6.0) and trilaurin (2\% at $\mathrm{pH} \mathrm{6.8).} \mathrm{Only} \mathrm{the} \mathrm{corresponding} \mathrm{methylketone} \mathrm{with}$ one less carbon atom was detected in each case. The oxidation of these triglycerides followed the same pattern as that of trihexanoin (Fig. 3), i.e. methylketone formation increased after an initial lag of 6-12 hr to a maximum after 6-10 days; after which the methylketone itself was slowly metabolized.

(a) $\mathrm{pH} 5 \cdot 3$

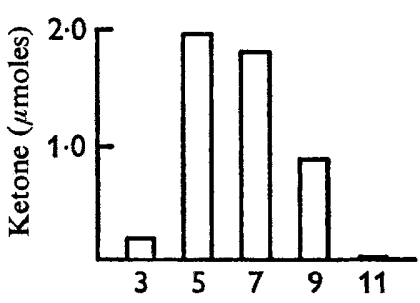

(b) $\mathrm{pH} 6.0$

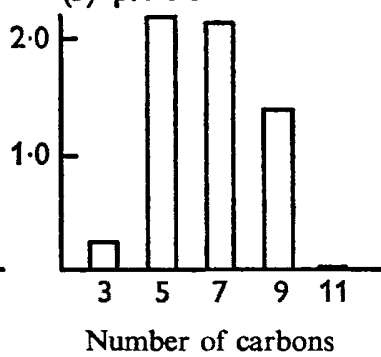

(c) $\mathrm{pH} 6.8$

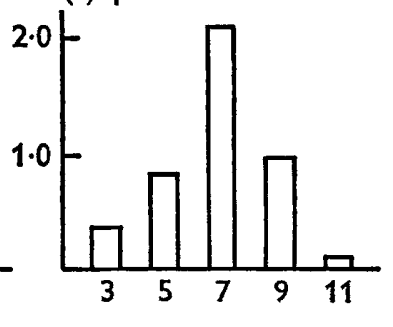

Fig. 7. Formation of methylketones from triglycerides ( $30 \mu$ moles) by washed 7 -day spores $\left(3 \times 10^{\circ}\right)$ of Penicillium roqueforti at $(a) \mathrm{pH} 5 \cdot 3,(b) \mathrm{pH} 6 \cdot 0,(\mathrm{c}) \mathrm{pH} 6 \cdot 8(200 \mu$ moles phosphate buffer) in presence of Casamino acids $(0 \cdot 1 \mathrm{~g})$. Total volume $10 \mathrm{ml}$.

The ability of amino acids to stimulate the oxidation of trihexanoin to pentan-2-one by spores was most pronounced at $\mathrm{pH} 5.5$ (Table 2 ) although only the basic amino acids arginine and lysine showed markedly decreased stimulatory activity at pH 6.5.

Trilaurin is solid at $30^{\circ}$, the temperature used in this work, which may have accounted for the low rate at which it was oxidized (Fig. 7). The water-soluble Tween 20 (polyoxyethylene sorbitan monolaurate), which contains approximately $60 \%$ lauric acid, was not, however, rapidly oxidized by spores in the presence of Casamino acids, the maximum yield of undecan-2-one obtained being less than $2 \%$ at pH 6.8.

\section{Effect of some enzyme inhibitors}

Sodium azide and 2,4-dinitrophenol, which are considered to disrupt the development of transport systems by uncoupling oxidative phosphorylation mechanisms (Quastel, 1964), also inhibited the formation of pentan-2-one from trihexanoin (Table 3) and from hexanoic acid by spores activated by Casamino acids. Sodium azide was the more effective inhibitor and it also completely inhibited the growth of mycelium. On the other hand high concentrations $\left(10^{-3} \mathrm{M}\right)$ of 2,4-dinitrophenol did not completely suppress the oxidation of triglycerides and was without effect upon mycelial growth.

Low concentrations $\left(10^{-5} \mathrm{M}\right)$ of the organophosphorus compound (E 600), which specifically inhibits hydrolytic mechanisms, partially suppressed the oxidation of 
triglycerides to methylketones but did not inhibit the growth of mycelium from spores activated by Casamino acids (Table 3). Compound E 600 was considerably more effective than di-isopropylfluorophosphate (DFP) against triglycerides, but neither compound inhibited to any significant extent the oxidation of fatty acids to methylketones. Chloramphenicol has been reported to inhibit bacterial esterases (Smith, Worrell \& Swanson, 1949) but even high concentrations were without effect on the oxidation of triglycerides or fatty acids by spores.

Table 2. Penicillium roqueforti: the effect of $p H$ value on the ability of amino acids to stimulate the formation of pentan-2-one from trihexanoin by washed spores

Each flask contained $3 \times 10^{9}$ spores, $200 \mu$ moles phosphate, $30 \mu$ moles trihexanoin, $200 \mu$ moles amino acid or $\mathbf{0 \cdot 1} \mathrm{g}$. Casamino acid, distilled water to $10 \mathrm{ml}$. Time of incubation $22 \mathrm{hr}$.

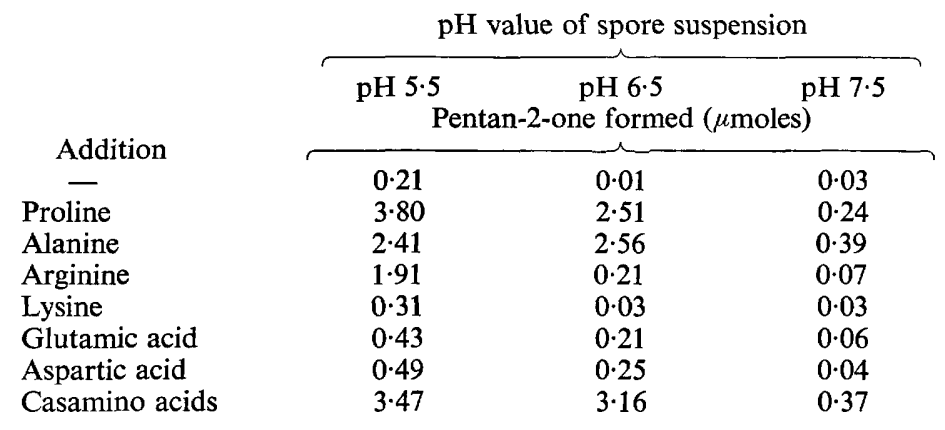

Table 3. Penicillium roqueforti: the effect of inhibitors on the formation of pentan-2-one from trihexanoin by spores activated by Casamino acids at pH $6 \cdot 0$

Each flask contained $3 \times 10^{9}$ spores, $200 \mu$ moles phosphate buffer (pH 6.0), $30 \mu$ moles trihexanoin, inhibitor as below, distilled water to $10 \mathrm{ml}$. Times of incubation as below.

\begin{tabular}{|c|c|c|c|c|}
\hline \multirow{2}{*}{ Inhibitor } & & \multicolumn{3}{|c|}{ Time of incubation (hr) } \\
\hline & & $\begin{array}{r}20 \mathrm{hr} \\
\mathrm{pe}\end{array}$ & $\begin{array}{l}44 \mathrm{hr} \\
\text { one }\end{array}$ & $20 \mathrm{hr}$ \\
\hline None & & $3 \cdot 07$ & $5 \cdot 22$ & + \\
\hline 2,4-dinitrophenol (M) & $\begin{array}{l}1 \times 10^{-4} \\
5 \times 10^{-4} \\
1 \times 10^{-3}\end{array}$ & $\begin{array}{l}1 \cdot 70 \\
1 \cdot 44 \\
0 \cdot 19\end{array}$ & $\begin{array}{l}4 \cdot 90 \\
3 \cdot 81 \\
0 \cdot 30\end{array}$ & $\begin{array}{l}+ \\
+ \\
+\end{array}$ \\
\hline Sodium azide $(M)$ & $\begin{array}{l}1 \times 10^{-4} \\
5 \times 10^{-4}\end{array}$ & $\begin{array}{l}\text { Nil } \\
\text { Nil }\end{array}$ & $\begin{array}{l}\text { Nil } \\
\text { Nil }\end{array}$ & - \\
\hline Chloramphenicol ( $\mu \mathrm{g} . / \mathrm{ml})$. & $\begin{array}{l}500 \\
1000\end{array}$ & $\begin{array}{l}3 \cdot 17 \\
3 \cdot 21\end{array}$ & $\begin{array}{l}5 \cdot 40 \\
5 \cdot 74\end{array}$ & $\begin{array}{l}+ \\
+\end{array}$ \\
\hline E $600(M) \dagger$ & $\begin{array}{l}10^{-4} \\
10^{-5}\end{array}$ & $\begin{array}{l}1 \cdot 61 \\
2 \cdot 65\end{array}$ & $\begin{array}{l}3 \cdot 34 \\
4 \cdot 22\end{array}$ & $\begin{array}{l}+ \\
+\end{array}$ \\
\hline DFP $(M) \div$ & $\begin{array}{l}10^{-4} \\
10^{-5}\end{array}$ & $\begin{array}{l}2 \cdot 40 \\
3 \cdot 14\end{array}$ & $\begin{array}{l}4 \cdot 77 \\
4 \cdot 96\end{array}$ & $\begin{array}{l}+ \\
+\end{array}$ \\
\hline
\end{tabular}




\section{Cell-free extracts of spores of Penicillium roqueforti}

A thick paste of spores and sand ground with buffer (see Methods) yielded an extract with slight esterase activity and which also slowly oxidized low concentrations of trioctanoin ( $3 \mu \mathrm{moles} / 10 \mathrm{ml}$.). Disintegration of a concentrated spore suspension by ultrasonic treatment for times up to $45 \mathrm{~min}$. resulted in inactive extracts.

\section{DISCUSSION}

Suspensions of washed spores of Penicillium roqueforti oxidized triglycerides extremely slowly but the addition of Casamino acids or certain amino acids (particularly L-proline or L-alanine) greatly stimulated oxidation after an initial lag of about $6 \mathrm{hr}$. The addition of other amino acids did not increase the effectiveness of L-proline, indicating that the pathway of activation was the same for all amino acids. The specificity of the stimulatory amino acids was very marked; L-hydroxyproline and L-phenylalanine had no effect during the first $24 \mathrm{hr}$ of incubation. Over extended periods, however, the formation of methylketones from triglycerides by spores was stimulated by the addition of a variety of sources of nitrogen, but to different degrees. The rate of oxidation was further increased by certain sugars (particularly D-galactose, D-xylose, D-glucose) although these were effective only in the presence of a nitrogen source. It may be significant that these three sugars all possess the same spatial configuration about carbon atoms 1, 2 and 3.

A source of nitrogen was essential for triglyceride oxidation by spores and for their germination, but not for the oxidation of fatty acids (Lawrence, 1966). Since cell-free extracts of spores possessed esterase activity it seems likely that the utilization of certain nitrogen compounds resulted in the transport of hydrolytic enzymes across the spore wall. One of the essential prerequisites to the formation of germ tubes is considered to be the accumulation of amino acids in the spore (Yanagita, 1957). The enhancement of the stimulatory affect of amino acids by certain sugars on spore germination and on triglyceride oxidation may be due therefore to a greater rate of transport of amino acids across the cell wall in the presence of an external source of energy; this has been shown to occur in bacterial and mammalian systems (Kepes \& Cohen, 1962; Scholefield, 1964). Similarly, 2,4-dinitrophenol and sodium azide may inhibit triglyceride oxidation by spores in the presence of Casamino acids by preventing the accumulation of exogenous amino acids in the spores, as has been shown for Escherichia coli (Kepes \& Cohen, 1962). Sodium azide, but not 2,4-dinitrophenol, also prevented the growth of mycelium. The differential sensitivity of various phosphorylation steps toward uncouplers is well established (e.g. Malkov \& Suprunenko, 1958) and 2,4-dinitrophenol is presumably more inhibitory to the phosphorylation processes involved in the metabolism of triglycerides than to other phosphorylations of vital importance in germ-tube growth.

The ability of fungal esterases to synthesize triglycerides has recently been shown (Iwai, Tsujisaka \& Fukumuto, 1964) but the results of the present work support the view that lipid metabolism is predominant during the early stages of germination (Farkas \& Ledingham, 1959). Factors which greatly stimulated the formation of methylketones from triglycerides by spores of Penicillium roqueforti also promoted the rapid germination of these spores, suggesting that similar mechanisms may be 
operating. Methylketone formation involves two hydrolytic steps: the initial liberation of fatty acid and the hydrolysis of the subsequently formed $\beta$-oxo acyl ester to the unesterified $\beta$-oxo acid. The insensitivity of fungal de-acylases to high concentrations of organophosphorus compounds observed in the present work confirms similar findings with de-acylases from mammalian tissues (Srere, Seubert \& Lynen, 1959). These inhibitors only partially suppressed methylketone formation from triglycerides and were without effect upon either fatty acid oxidation to methylketones or the germination of the spores. While such evidence is not conclusive it is consistent with the view (Lawrence, 1966) that de-acylation may play an important part in spore germination.

I would like to thank the Director of the National Institute for Research in Dairying for affording facilities for doing this work and to colleagues in the Bacteriology Department for helpful discussions and assistance.

\section{REFERENCES}

ACKLIN, O. (1929). The biochemistry of Penicillium glaucum. A contribution to the problem of methylketone formation from triglycerides or fatty acids in the metabolism of molds. Biochem. Z. 204, 253.

Alford, J. A., Pierce, D. A. \& Suggs, F. G. (1964). Action of microbial lipases on natural fats and synthetic triglycerides. J. Lipid Res. 5, 390.

Allen, P. J. (1965). Metabolic aspects of spore germination in fungi. A. Rev. Phytopathol. $3,313$.

Atkinson, T. G. \& Allen, P. J. (1966). Purification and partial characterization of a factor in cotton wax stimulating the germination of self-inhibited wheat stem rust uredospores. Pl. Physiol., Lancaster, 41, 28.

Cochrane, J. C., Cochrane, V. W., Simon, F. G. \& Spaeth, J. (1963). Spore germination and carbon metabolism in Fusarium solani. I. Requirements for spore germination. Phytopathology 53, 1155.

Cochrane, V. W., Cochrane, J. C., Collins, C. B. \& Serafin, F. G. (1963). Spore germination and carbon metabolism in Fusarium solani. II. Endogenous respiration in relation to germination. Am. J. Bot. 50, 806.

EkUndayo, J. A. \& CARLILE, M. J. (1964). The germination of sporangiospores of Rhizopus arrhizus; spore swelling and germ tube emergence. J. gen. Microbiol. 35, 261.

Farkas, G. L. \& Ledingham, G. A. (1959). The relation of self-inhibition of germination to the oxidative metabolism of stem rust uredospores. Can. J. Microbiol. 5, 141.

FODOR, P. J. \& CHARI, A. (1949). Ester hydrolysing enzyme systems of Aspergillus niger and Penicillium roqueforti. Enzymologia 13, 258.

GeHriG, R. F. \& KNIGHT, S. G. (1958). Formation of ketones from fatty acids by spores of Penicillium roqueforti. Nature, Lond. $182,1937$.

GeHRIG, R. G. \& KNIGHT, S. G. (1963). Fatty acid oxidation by spores of Penicillium roqueforti. Appl. Microbiol. 11, 166.

Goodman, J. J. (1950). Adaptive production of amylase and lipase by three species of fungi. Science, N.Y. 112, 176.

Grover, R. K. (1964). The effect of amino acids on growth and sporulation of Aspergillus flavus and their carry-over for subsequent spore germination. New Phytol. 63, 12.

IMAMURA, T. \& KATAOKA, K. (1963). Biochemical studies on the manufacturing of Roquefort type cheese. I. Lipase-producing ability of Penicillium roqueforti. Jap. J. zootech. Sci. 34, 344.

Iwai, M., Tsujisaka, Y. \& Fukumuto, J. (1964). Studies on lipase. II. Hydrolytic and esterifying actions of crystalline lipase of Aspergillus niger. J. gen. appl. Microbiol. 10, 13.

JACK, R. C. (1964). Characterisation of Glomerella cingulata lipids. Pl. Physiol., Lancaster, 39 (Suppl.), xxiv.

KePes, A. \& Cohen, G. N. (1962). The physiology of growth. In The Bacteria, vol. 4, chap. 5. New York and London: Academic Press.

LAWrence, R. C. (1965a). Activation of spores of Penicillium roqueforti. Nature, Lond. $205,801$.

LAWRENCE, R. C. $(1965 b)$. Use of 2,4-dinitrophenylhydrazine for the estimation of micro amounts of carbonyls. Nature, Lond. 205, 1313. 
LAWRENCE, R. C. (1966). The oxidation of fatty acids by spores of Penicillium roqueforti. J. gen. Microbiol. 44, 393.

LAWRENCE, R. C., FrYER, T. F. \& ReITER, B. (1966). A rapid method for the quantitative estimation of microbial lipases. Nature, Lond. 44, 393.

Malkov, A. M. \& SuprunenKo, A. I. (1958). The effect of 2,4-dinitrophenol on aerobic fermentation and synthesis of pyrophosphoric compounds in multiplying yeasts. (Orig. in Russian.) Mikrobiologiya 27, 12.

MILLER, L. P. (1962). L-proline and L-alanine as substitutes for higher temperatures in the germination of fungus spores. Phytopathol. 52, 743. (Abstr.)

MorRIs, H. A. \& JeZESKI, J. J. (1953). The action of microorganisms on fats. II. Some characteristics of the lipase system of Penicillium roqueforti. J. Dairy Sci. 36, 1285.

O'LeARY, W. M. \& Weld, Julia, T. (1964). Lipolytic activities of Staphylococcus aureus. 1. Nature of the enzyme producing free fatty acids from plasma lipids. $J$. Bact. 88, 1356.

QUASTEL, J. H. (1964). Transport reactions at the cell membrane. Can. J. Biochem. 42, 907.

SCHOLEFIELD, P. G. (1964). The role of adenosine triphosphate in transport reactions. Can. J. Biochem. 42, 917.

SMITH, G. N., Worrell, C. S. \& SwANSON, A. L. (1949). Inhibition of bacterial esterases by chloramphenicol (chloromycetin). J. Bact. 55, 803.

Srere, P. A., Seubert, W. \& Lynen, F. (1959). Palmityl coenzyme A deacylase. Biochim. biophys. Acta 33, 313.

THALER, H. \& EIsenLoHr, W. (1941). The breakdown of saturated fatty acid triglycerides to methyl ketones by Penicillium glaucum. Fette Seifen 48, 316.

WeBER, D. J. (1962). The role of proline in the germination of Rhizopus stolonifer spores. Phytopathology (Abstr.), 52, 756.

Weber, D. J. \& OGAWA, J. M. (1965). The specificity of proline in the germination of spores of Rhizopus arrhizus. Phytopathology 55, 262.

YANAGTTA, T. (1957). Biochemical aspects of the germination of conidiospores of Aspergillus niger. Arch. Mikrobiol. 26, 329. 